\title{
Akinetic Mutism Caused by HIV-associated Progressive Multifocal Leukoencephalopathy was Successfully Treated with Mefloquine: A Serial Multimodal MRI Study
}

\author{
Kasane Naito ${ }^{1,2}$, Hiroki Ueno ${ }^{1}$, Mayu Sekine ${ }^{1,3}$, Munekazu Kanemitsu ${ }^{1}$, Tomohiko Ohshita ${ }^{1,4}$, \\ Takeshi Nakamura ${ }^{1}$, Takemori Yamawaki ${ }^{1}$ and Masayasu Matsumoto ${ }^{1}$
}

\begin{abstract}
We report a case of a patient with highly active anti-retroviral therapy-resistant human immunodeficiency virus (HIV)-associated progressive multifocal leukoencephalopathy (PML). The patient showed an improvement in imaging findings and clinical symptoms after mefloquine was introduced as an additional treatment. Serial assessment of white matter lesions was conducted by proton magnetic resonance spectroscopy $\left({ }^{1} \mathrm{H}-\right.$ MRS) and diffusion-weighted imaging (DWI). As the clinical symptoms improved, the $\mathrm{N}$-acetylaspartate/creatine ratio increased, the choline/creatine ratio decreased, and the elevated ADC value decreased. These concomitant changes suggested that ${ }^{1} \mathrm{H}-\mathrm{MRS}$ and DWI were useful for the assessment of the therapeutic effect on PML.
\end{abstract}

Key words: progressive multifocal leukoencephalopathy (PML), human immunodeficiency virus infection (HIV), highly active anti-retroviral therapy (HAART), mefloquine, proton magnetic resonance spectroscopy ('H-MRS), apparent diffusion coefficient (ADC)

(Intern Med 51: 205-209, 2012)

(DOI: 10.2169/internalmedicine.51.6253)

\section{Introduction}

Progressive multifocal leukoencephalopathy (PML) is a demyelinating disease of the central nervous system caused by JC virus (JCV). PML occurs among immunocompromised patients with leukemic disease, malignant lymphoma, human immunodeficiency virus (HIV) infection or patients receiving immunosuppressive therapy. HIV-induced immunodeficiency is the most common precipitating condition that leads to PML, and in an analysis of 9,675 cases of PML in the US Nationwide Inpatient Sample database (1), it was reported that HIV-associated PML (HIV-PML) accounted for $82 \%$ of all PML cases. Highly active antiretroviral therapy (HAART), which uses a combination of more than three drugs, is a central component for the treatment of HIV and is effective for prolonging the life of pa- tients. Obviously, the introduction of HAART is also effective for prolonging the life of HIV-PML patients (2). On the other hand, the frequency of PML has not decreased as compared to other opportunistic infections (3), and HAART is not effective for about $50 \%$ of HIV-PML patients (2). In 2009, the anti-malarial drug mefloquine was revealed to have anti-JCV activity in in vitro culture (4). Some cases in which mefloquine has had an effect on PML have been reported $(5,6)$; however, there is no detailed report that mefloquine has an effect in HIV-PML. There have been many reports of using diffusion-weighted imaging (DWI) and proton magnetic resonance spectroscopy ('H-MRS) for imaging PML; however, there are only a few studies on white matter lesions assessed by ${ }^{1} \mathrm{H}-\mathrm{MRS}$ during the therapeutic period. We studied the serial changes of ${ }^{1} \mathrm{H}-\mathrm{MRS}$ and DWI in white matter lesions of a patient with HAART-resistant HIV-PML to whom mefloquine was introduced.

\footnotetext{
${ }^{1}$ Department of Clinical Neuroscience and Therapeutics, Hiroshima University, Graduate School of Biomedical Sciences, Japan, ${ }^{2}$ Department of Neurology, Hiroshima City Hospital, Japan, ${ }^{3}$ Department of Neurology, Tokyo Saiseikai Central Hospital, Japan and ${ }^{4}$ Department of Neurology, Suiseikai Kajikawa Hospital, Japan

Received for publication July 25, 2011; Accepted for publication September 29, 2011

Correspondence to Dr. Hiroki Ueno, hirokiueno@hiroshima-u.ac.jp
} 

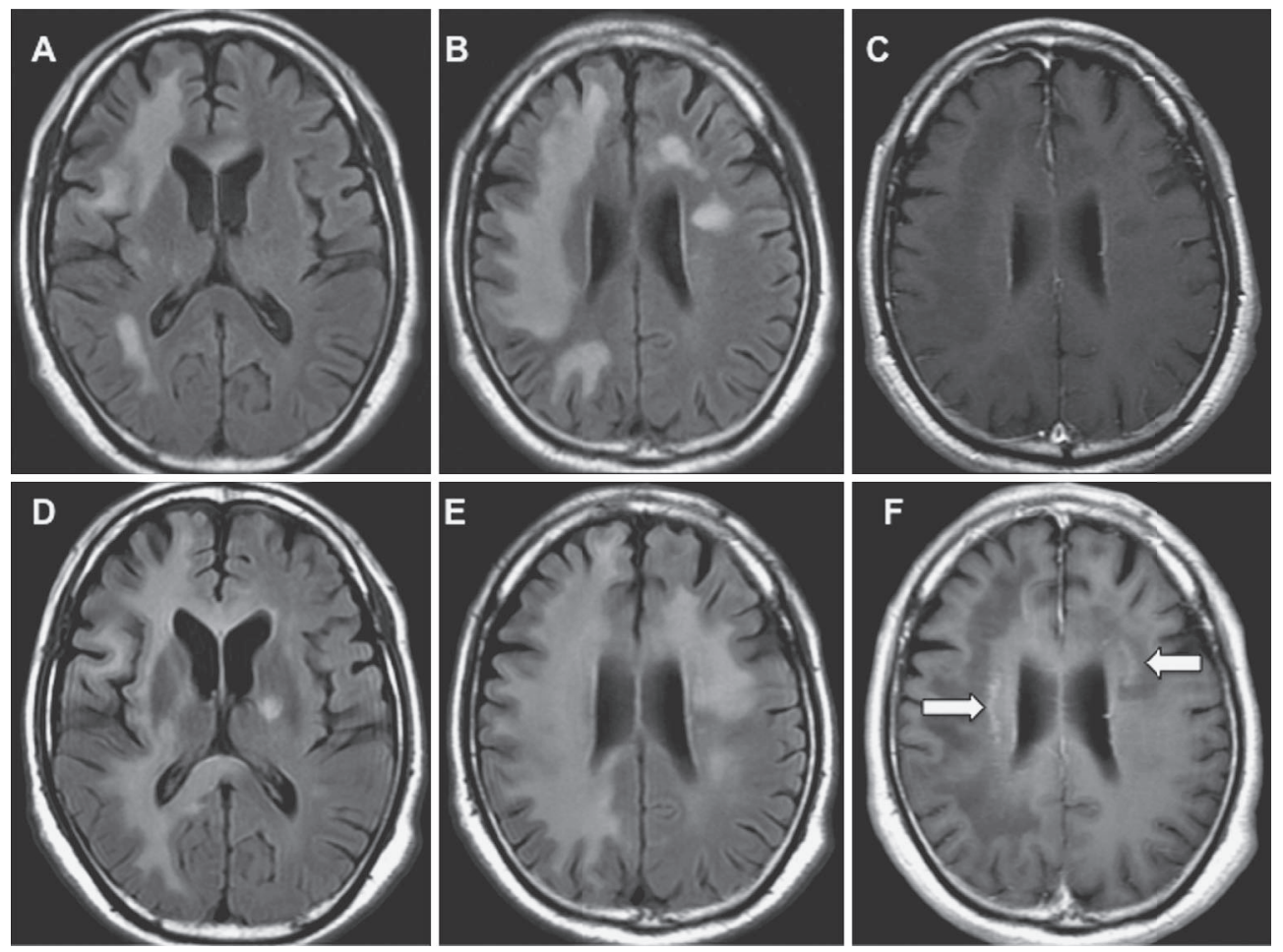

Figure 1. A, B and $\mathrm{C}$ show the initial MR study at admission (3 months after onset). A fluid attenuation inversion recovery (FLAIR) image showed hyperintense signals in the bilateral fronto-parietal white matter (A, B). A T1-weighted post-gadolinium contrast image showed no enhancement (C). D, E and F show the follow-up MR study 8 months after onset (5 weeks after initiation of mefloquine). A FLAIR image showed progression of white matter abnormalities (D, E). A T1-weighted post-gadolinium contrast image showed diffuse enhancement of white matter abnormalities (arrows) (F).

\section{Case Report}

A 55-year-old man presented with memory impairment and communication disorder in January 2010. His cognitive dysfunction worsened, and he was admitted to our hospital in mid-March. Clinical examination revealed attention disturbance, left hemispatial neglect, apraxia, memory impairment and dysarthria. The patient did not show any signs of paralysis or involuntary movement, and muscle tonus and tendon reflexes were normal. The white blood cell count was $4.58 \times 10^{3} / \mu \mathrm{L}$ (CD4+ lymphocyte: $187 / \mu \mathrm{L}, \mathrm{CD} 8+$ lymphocyte: $1,070 / \mu \mathrm{L})$, HIV antibodies were positive, and HIV RNA was $50.0 \times 10^{3}$ copies $/ \mathrm{mL}$ in his blood. An examination of the cerebrospinal fluid (CSF) showed increased protein concentration $(88 \mathrm{mg} / \mathrm{dL})$ and a normal cell count $(2 / \mu \mathrm{L}$ with all mononuclear cells), and real-time polymerase chain reaction (PCR) for JCV DNA in the CSF yielded positive results, showing 535,500 copies $/ \mathrm{mL}$. On admission MRI (Signa Excite HD 3.0 T: GE Medical Systems) showed T2 and fluid attenuated inversion recovery (FLAIR) asymmetrical high signals in the cerebral bilateral white matter, and the cortex was almost completely intact although the lesion involved the U-fibers. DWI ( $b$-value, $1,000 \mathrm{~s} / \mathrm{mm}^{2}$ ) showed high signals in the part of hyperintense lesion on $\mathrm{T} 2 \mathrm{WI} /$
FLAIR. MR imaging did not show any gadolinium enhancement (Fig. 1A, B, C). MRS using the GE technique PROBE with PRESS; TR 2,000 ms; TE $144 \mathrm{~ms}$ was performed, as well. The ${ }^{1} \mathrm{H}-\mathrm{MR}$ spectrum was acquired from a localized voxel of interest outlined in an axial FLAIR image of the right frontal periventricular white matter lesion. The voxel size was $20 \times 20 \times 20 \mathrm{~mm}$ (volume, $8 \mathrm{~cm}^{3}$ ). ${ }^{1} \mathrm{H}-\mathrm{MRS}$ showed a substantially reduced $\mathrm{N}$-acetylaspartate (NAA)/creatine $(\mathrm{Cr})$ ratio $(\mathrm{NAA} / \mathrm{Cr}=0.57)$ and an elevated choline $(\mathrm{Cho}) /$ creatine ratio $(\mathrm{Cho} / \mathrm{Cr}=1.76)$ (Fig. 2A, B). On the apparent diffusion coefficient map (ADC map), ADC values were measured in five regions of interest in the right frontal periventricular white matter lesion, and the values were found to increase slightly (range 0.84 to 1.04 , mean value $0.94 \times 10^{-3} \mathrm{~mm}^{2} / \mathrm{s}$ ) (Fig. 2C, D). Probable PML associated with HIV infection was diagnosed.

HAART was initiated in April 2010, four months after the onset of symptoms. Following treatment, the HIV-RNA level decreased, but CD4+ lymphocytes were under 200/ $\mu \mathrm{L}$ throughout the course and did not show substantial elevation. The MRI findings and clinical manifestations deteriorated, and the patient developed left flaccid hemiplegia and experienced akinetic mutism. In June 2010, about six months after the onset, treatment with mefloquine hydrochloride tablets was started at $275 \mathrm{mg} /$ day orally for three 

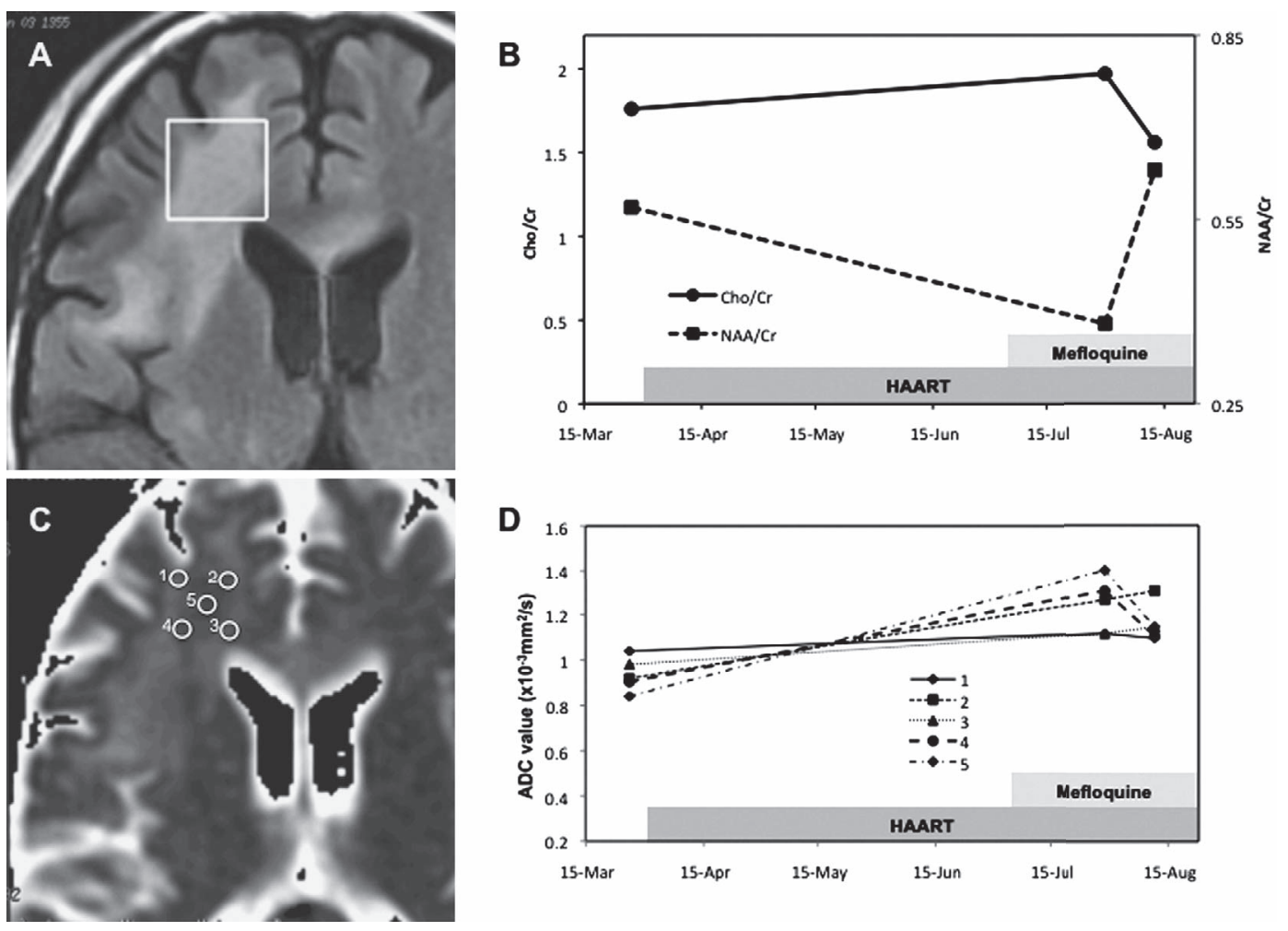

Figure 2. ${ }^{1}$ H-MRS and DWI were performed on March 26, July 29 and August 11. A. ${ }^{1}$ H-MR spectrum acquired from a localized voxel of interest outlined on an axial FLAIR image of the right frontal periventricular white matter lesion. B. Serial change of ${ }^{1} \mathrm{H}-\mathrm{MRS}$ at three time points. The third ${ }^{1} \mathrm{H}$-MRS ( 5 weeks after the initiation of mefloquine) showed an increased ratio of $\mathrm{N}$-acetylaspartate (NAA) and a decreased ratio of choline (Cho) to creatine (Cr) with improvement of symptoms. C. The ADC value was measured in the apparent diffusion coefficient map (ADC map) in five regions of interest (i.e., 1-5) in the right frontal periventricular white matter lesion. $D$. Serial changes of the ADC value at three time points. ADC values showed a slight upward tendency, whereas some ADC values (i.e. 1,4,5) decreased at the third DWI study.

days and was then continued at $275 \mathrm{mg}$ once a week. This course followed the administration protocol of Kishida et al (7) as a modification of the Biogen Idec mefloquine treatment protocol taken from the clinicaltrials.gov website (8). According to the instructions of the ethical review board at Hiroshima University Hospital, informed consent regarding the use of mefloquine was obtained from the patient's family prior to introduction of the therapy. About eight months after the onset, and five weeks after mefloquine was started, the patient showed some improvement of clinical symptoms, and an MRI revealed enhancing white matter lesions (Fig. 1D, E, F). ${ }^{1} \mathrm{H}-\mathrm{MRS}$ of the right frontal lesion showed a further reduction in NAA (NAA/Cr=0.38) and elevated Cho $(\mathrm{Cho} / \mathrm{Cr}=1.97$ ) (Fig. 2B). All ADC values showed an increasing trend, and the mean $\mathrm{ADC}$ value was $1.244 \times 10^{-3}$ $\mathrm{mm}^{2} / \mathrm{s}$ (range 1.12 to $1.40 \times 10^{-3} \mathrm{~mm}^{2} / \mathrm{s}$ ) (Fig. 2D). The patient's clinical condition continued to improve, and he began to let out a single tone and showed improved muscle strength in his left arm and leg. ${ }^{1} \mathrm{H}$-MRS performed seven weeks after mefloquine was introduced showed recoveries of reduced NAA (NAA/Cr=0.63) and elevated $\mathrm{Cho}(\mathrm{Cho} / \mathrm{Cr}=$ 1.56) in comparison to the levels at admission (Fig. 2B). Several ADC values showed a slight decreasing trend, and the mean $\mathrm{ADC}$ value was $1.164 \times 10^{-3} \mathrm{~mm}^{2} / \mathrm{s}$ (range 1.10 to $1.31 \times 10^{-3} \mathrm{~mm}^{2} / \mathrm{s}$ ) (Fig. 2D). Eight weeks after mefloquine was introduced, CSF PCR findings for JCV were negative. In August 2010, the patient was transferred to another hospital.

\section{Discussion}

Compared with the era before combined anti-retroviral therapy, the incidence and mortality of HIV-PML are currently reduced; however, HIV-PML is still a fatal disease due to the treatment-resistant cases. Several factors are considered to be involved in HIV-PML prognosis including CD4+ T cell count. Marzocchetti et al (9) reported that the estimated 1-year survival rate was $48 \%$ in HIV-positive PML patients with a CD4 count $<200 / \mu \mathrm{L}$ at PML diagnosis compared to $67 \%$ in those with a CD4 count $>200 / \mu \mathrm{L}$. In addition, JC viral load in the CSF can be attributed to longterm survival. In a study of 61 HIV-infected patients with PML, Bossolasco et al (10) reported that JCV DNA levels of $>3.64 \log$ copies $/ \mathrm{mL}$ were significantly correlated with a shorter survival. And thus the reasons for the resistance to HAART in the present case may include low-CD4+ T cell 
counts and high levels of JCV DNA during therapeutic period.

Recently, the anti-malarial drug mefloquine, which is considered to have anti-JCV action, is expected to have an effect on PML, and a randomized study is currently underway (8). Gofton et al (5) reported a patient with sarcoidosis who was treated with $1,000 \mathrm{mg} /$ week mefloquine that was initiated six months after symptom onset. Clinical progression stopped immediately, and the JC virus then became undetectable in the CSF. Kishida and Tanaka (6) reported a patient after an umbilical cord blood transplant that showed favourable clinical, neuroradiological and virological responses after the initiation of mefloquine. To our knowledge, the present case is the first detailed report that demonstrates that mefloquine combined with HARRT gave a positive outcome to a patient with HIV-PML. Although mefloquine was initiated six months after symptom onset, the result implies that mefloquine has the ability to improve symptoms of HAART-resistant PML even in the chronic phase.

Image findings in PML reflect demyelination and provide helpful information for diagnosis. Contrast enhancement is usually absent in classic PML lesions on MRI because the lesions are oligodendrocyte cell death caused by persistent JCV infection, which indicates that the lesions are not associated with inflammation. It is possible that contrast enhancement in PML is caused by mechanisms of the inflammatory response induced when JCV is eliminated by the immune system. When this response causes massive cellular destruction after initiation of HAART, an HIV-PML patient's clinical condition sometimes becomes worse. This worsening is known as immune reconstitution inflammatory syndrome. However, once JCV is eliminated by the immune system, an improvement in the prognosis can be expected. There are reports that contrast enhancement is a favourable treatment response $(11,12)$ and associated with a longer survival (13-15). In the present case, the PML was advanced, because the CD4+ T cell count did not increase, and the immune system did not recover only by HAART. About five weeks after mefloquine was initiated, an MRI showed an enhancing lesion corresponding to symptomatic improvement. This MRI finding may imply an inflammatory response against JCV-infected cells in the lesion.

There have been some studies on white matter lesions using DWI. It has been shown that the ADC value in a recent lesion and an advancing edge of established lesion decreases, and the ADC value in an old lesion and in the center of the lesion increases (16-18). In the present case, as the clinical condition became worse, the elevated ADC value in the lesion showed a further increase in spite of HAART. In PML lesions, an increased ADC value indicates pathologically enlarged extracellular space and a loss of myelin (17). There are some reports of serial ADC value changes in PML patients treated with HAART $(18,19)$. Usiskin et al (18) reported an HIV-PML patient who presented a decreased ADC value with a favourable response to therapy, and they sug- gested that the change implied microstructural reorganization. In the present case, the ADC value also decreased slightly with an improvement in the clinical condition after the introduction of mefloquine. There is a possibility that facilitated diffusion becoming slightly more restricted shows remyelination in the white matter lesion.

Early ${ }^{1} \mathrm{H}$-MRS studies of patients with PML have revealed that decreased NAA concentrations [which indicate neuronal damage (20)], elevated Cho (which indicates demyelination), and the appearance of a lactate peak (which indicates impaired energy metabolism) (21-23). In the present case, serial changes of ${ }^{1} \mathrm{H}-\mathrm{MRS}$ were observed. ${ }^{1} \mathrm{H}-$ MRS performed seven weeks after mefloquine was introduced revealed elevated $\mathrm{NAA} / \mathrm{Cr}$ and reduced $\mathrm{Cho} / \mathrm{Cr}$, reflecting an improvement in clinical symptoms. This change may indicate a functional improvement of infected oligodendrocytes by anti-JCV effects of mefloquine. Several studies have demonstrated that a decrease of NAA could be partially reversible in acute demyelinating lesions (such as those that occur in multiple sclerosis patients) (24-26).

There is a possibility that mefloquine is effective in the chronic phase of HAART-resistant cases of HIV-PML. The present results suggest that, in addition to contrast enhancement, DWI and ${ }^{1} \mathrm{H}-\mathrm{MRS}$ may offer valuable information on the microstructural reorganization process that occurs after mefloquine inhibits oligodendrocyte death.

\section{The authors state that they have no Conflict of Interest (COI).}

\section{Acknowledgement}

The authors are grateful to Dr. Kazuo Nakamichi and Dr. Masayuki Saijo (Department of Virology 1, National Institute of Infectious Diseases) for determinations of JCV in CSF and Dr. Motohiro Yukitake (Division of Neurology, Department of Internal Medicine Faculty of Medicine, Saga University) for helpful suggestions on the use of mefloquine.

\section{References}

1. Molloy ES, Calabrese LH. Progressive multifocal leukoencephalopathy: a national estimate of frequency in systemic lupus erythematosus and other rheumatic diseases. Arthritis Rheum 60: 37613765, 2009.

2. Antinori A, Cingolani A, Lorenzini $P$, et al. Italian Registry Investigative Neuro AIDS Study Group. Clinical epidemiology and survival of progressive multifocal leukoencephalopathy in the era of highly active antiretroviral therapy: data from the Italian Registry Investigative Neuro AIDS (IRINA). J Neurovirol 9: 47-53, 2003.

3. Koralnik IJ. New insights into progressive multifocal leukoencephalopathy. Curr Opin Neurol 17: 365-370, 2004.

4. Brickelmaier M, Lugovskoy A, Kartikeyan R, et al. Identification and characterization of mefloquine efficacy against JC virus in vitro. Antimicrob Agents Chemother 53: 1840-1849, 2009.

5. Gofton TE, Al-Khotani A, O'Farrell B, Ang LC, McLachlan RS. Mefloquine in the treatment of progressive multifocal leukoencephalopathy. J Neurol Neurosurg Psychiatry 82: 452-455, 2011.

6. Kishida S, Tanaka K. Mefloquine treatment in a patient suffering from progressive multifocal leukoencephalopathy after umbilical cord blood transplant. Intern Med 49: 2509-2513, 2010.

7. Kishida S, Tanaka K, Ajisawa A, et al. Annual report of the re- 
search committee on prion disease and slow virus infection, research on measures for intractable diseases health and labour sciences research grants, the Ministry of Health. Labour and Welfare of Japan, 2010: 125-132 (in Japanese).

8. Clinical Trials.gov [Internet]. Maryland: U.S. National Institutes of Health; c1993- [updated 2011 July 7; cited 2011 Jul 25]. Study to Explore the Effect of Mefloquine in Subjects with Progressive Multifocal Leukoencephalopathy (PML). Available from: http:// clinicaltrials.gov/ct2/show/NCT00746941

9. Marzocchetti A, Tompkins T, Clifford DB, et al. Determinants of survival in progressive multifocal leukoencephalopathy. Neurology 73: 1551-1558, 2009.

10. Bossolasco S, Calori G, Moretti F, et al. Prognostic significance of JC virus DNA levels in cerebrospinal fluid of patients with HIVassociated progressive multifocal leukoencephalopathy. Clin Infect Dis 40: 738-744, 2005.

11. Thurnher MM, Post MJ, Rieger A, Kleibl-Popov C, Loewe C, Schindler E. Initial and follow-up MR imaging findings in AIDSrelated progressive multifocal leukoencephalopathy treated with highly active antiretroviral therapy. AJNR Am J Neuroradiol 22: 977-984, 2001.

12. Du Pasquier RA, Koralnik IJ. Inflammatory reaction in progressive multifocal leukoencephalopathy: harmful or beneficial? J Neurovirol 9: 25-31, 2003.

13. Berger JR, Levy RM, Flomenhoft D, Dobbs M. Predictive factors for prolonged survival in acquired immunodeficiency syndromeassociated progressive multifocal leukoencephalopathy. Ann Neurol 44: 341-349, 1998.

14. Arbusow V, Strupp M, Pfister HW, Seelos KC, Brückmann H, Brandt T. Contrast enhancement in progressive multifocal leukoencephalopathy: a predictive factor for long-term survival? J Neurol 247: 306-308, 2000.

15. Küker W, Mader I, Nägele $T$, et al. Progressive multifocal leukoencephalopathy: value of diffusion-weighted and contrastenhanced magnetic resonance imaging for diagnosis and treatment control. Eur J Neurol 13: 819-826, 2006.

16. Mader I, Herrlinger U, Klose U, Schmidt F, Küker W. Progressive multifocal leukoencephalopathy: analysis of lesion development with diffusion-weighted MRI. Neuroradiology 45: 717-721, 2003.
17. Bergui M, Bradac GB, Oguz KK, et al. Progressive multifocal leukoencephalopathy: diffusion-weighted imaging and pathological correlations. Neuroradiology 46: 22-25, 2004.

18. Usiskin SI, Bainbridge A, Miller RF, Jäger HR. Progressive multifocal leukoencephalopathy: serial high-b-value diffusion-weighted MR imaging and apparent diffusion coefficient measurements to assess response to highly active antiretroviral therapy. AJNR Am J Neuroradiol 28: 285-286, 2007.

19. Buckle C, Castillo M. Use of diffusion-weighted imaging to evaluate the initial response of progressive multifocal leukoencephalopathy to highly active antiretroviral therapy: early experience. AJNR Am J Neuroradiol 31: 1031-1035, 2010.

20. Nakano M, Ueda H, Li JY, Matsumoto M, Yanagihara T. Measurement of regional $\mathrm{N}$-acetylaspartate after transient global ischemia in gerbils with and without ischemic tolerance: an index of neuronal survival. Ann Neurol 44: 334-340, 1998.

21. Iranzo A, Moreno A, Pujol J, et al. Proton magnetic resonance spectroscopy pattern of progressive multifocal leukoencephalopathy in AIDS. J Neurol Neurosurg Psychiatry 66: 520-523, 1999.

22. Chang L, Ernst T, Tornatore C, et al. Metabolite abnormalities in progressive multifocal leukoencephalopathy by proton magnetic resonance spectroscopy. Neurology 48: 836-845, 1997.

23. Cuvinciuc V, Martin-Blondel G, Marchou B, et al. Proton MR Spectroscopy of progressive multifocal leukoencephalopathyimmune reconstitution inflammatory syndrome. Am J Neuroradiol 31: 69-70, 2010.

24. Narayanan S, De Stefano N, Francis GS, et al. Axonal metabolic recovery in multiple sclerosis patients treated with interferon beta1b. J Neurol 248: 979-986, 2001.

25. Matsui N, Nakane S, Harada M, et al. Neuroradiological study of a possible progressive multifocal leukoencephalopathy using diffusion tensor imaging and proton magnetic resonance spectroscopy. Rinsho Shinkeigaku (Clin Neurol) 46: 555-560, 2006 (in Japanese, Abstract in English).

26. Dreha-Kulaczewski SF, Helms G, Dechent P, Hofer S, Gärtner J, Frahm J. Serial proton MR spectroscopy and diffusion tensor imaging in infantile Balo's concentric sclerosis. Neuroradiology 51: 113-121, 2009.

(C) 2012 The Japanese Society of Internal Medicine http://www.naika.or.jp/imindex.html 